\section{Torsades de pointes after terfenadine-itraconazole interaction}

Drs S Pohjola-Sintonen, M VittaSAlo, L Tolvonen, and P Neuvonen (Helsinki University Central Hospital, Helsinki, Finland) write: Terfenadine is a non-sedating antihistamine, available without prescription in many countries. We report torsades de pointes ventricular tachycardia occurring in a healthy woman who was treated with regular doses of terfenadine and itraconazole, an antifugal agent. As far as we know this is the first report of interaction between terfenadine and itraconazole.

A 26 year old woman had been taking terfenadine $60 \mathrm{mg}$ twice daily for eight days for relapsing sinusitis when she began taking itraconazole $100 \mathrm{mg}$ twice daily for vaginitis. On the third evening of the concomitant medication she started to have syncopal episodes. On admission to hospital next morning her electrocardiogram showed a QT-interval of $580 \mathrm{~ms}$ at a heart rate of 67 beats $/ \mathrm{min}$. Several bursts of torsades de pointes ventricular tachycardia were documented, two of them associated with syncope. Serum electrolyte concentrations were normal. Terfenadine and itraconazole were discontinued and propranolol started. She was also taking oral contraceptives, which were not stopped. No more arrhythmias were seen 20 hours after the last terfenadine tablet. The QTinterval gradually returned to normal within three days.

The patient was small $(152 \mathrm{~cm}$, $44 \mathrm{~kg}$ ), and physical examination revealed no abnormal findings. Liver function values were normal. The electrocardiograms of her family members exhibited normal QTintervals. Exercise test, echocardiogram, 24 hour ambulatory electrocardiographic monitoring, antimyosin scanning, and electrophysiological testing all gave normal results. Propranolol was discontinued.

Five serum samples, taking 19-84 hours after the last dose of terfenadine, consistently showed impaired metabolism of terfenadine. Unmetabolised terfenadine is normally undetectable-that is $<10 \mu \mathrm{g} / \mathrm{l}$ in plasma, but it was detected up to 60 hours $(12 \mu \mathrm{g} / \mathrm{l})$ after the last tablet of terfenadine. The first serum sample contained $28 \mu \mathrm{g} / \mathrm{l}$. The highest level of terfenadine's acid (main) metabolite was $160 \mathrm{pg} / \mathrm{l}$ which, although high for the 19 hour value, did not exceed the peak concentrations recorded in a study of subjects given $60 \mathrm{mg}$ of terfenadine twice daily.' The elimination half life of the metabolite was about 36 hours (normal 17 hours), showing its delayed elimination.

So far terfenadine toxicity has been described only in overdose ${ }^{23}$ or during simultaneous treatment with ketoconazole, ${ }^{45}$ which impairs the liver metabolism of terfenadine. Macrolide antibiotics have a similar though smaller, effect. ${ }^{1}$ According to the manufacturer, oral contraceptives do not interfere with terfenadine metabolism. Our patient had not taken antibiotics during the past two weeks and an intrinsic cardiac or metabolic disorder was ruled out. The most probable factor impairing terfenadine metabolism was the simultaneous use of itraconazole.

We thank Marion Merrel Dow laboratory in Uxbridge, United Kingdom, for performing the determinations of the serum concentrations of terfenadine and acid metabolite.

Matthews DR, McNutt B, Okerholm $R$ Flicker M, McBride G. Torsades de pointes Th, 19.

2 Davies AJ, Harindra V, McEvan A, Ghose RR. Cardiotoxic effect with convulsions in terfenadine overdose. BMF 1989;298:325.

3 MacConnell TJ, Stanners AJ. Torsades de pointes complicating treatment with terfenadine. BMF 1991;302:1469.

4 Monahan BP, Ferguson CL, Killeavy ES, Lloyd BK, Troy J, Cantilena LR. Torsades de pointes occurring in association with terfenadine use. $¥ A M A$ 1990;264:2788-90.

5 Zimmerman $M$, Duruz H, Broccard O, Levy D, Lacatis D, Bloch A. Torsades de pointe D Ler treatment conazole. Eur Hear f 1992;13:1002-3.

\section{Syndrome of inappropriate secretion of antidiuretic} hormone induced by diclofenac

Drs $\mathrm{N}$ T Cheung, $S$ Coley, $\mathrm{T}$ SheERAN, and $R$ D Situnayake (Department of Rheumatology, Dudley Road Hospital, Birmingham B18 7QH) write: An 82 year old woman with rheumatoid arthritis developed biochemical features mimicking the syndrome of inappropriate secretion of antidiuretic hormone due to the non-steroidal anti-inflammatory drug diclofenac sodium. She had been treated with various non-steroidal anti-inflammatory drugs since 1983 and during this period her serum sodium concentration ranged between 126 and $136 \mathrm{mmol} / \mathrm{h}$. Diclofenac sodium $100 \mathrm{mg}$ daily was started in March 1988. Concomitant medication consisted of ranitidine $150 \mathrm{mg}$ twice daily, lorazepam $1 \mathrm{mg}$ at night, dothiepin $25 \mathrm{mg}$ at night, and coproxamol 2 tablets three times a day. Her history included a fracture of the right hip, diverticular disease, and oesophageal reflux. In November 1991 she presented with sudden onset of lower back pain. She was alert, oriented, and well hydrated. Blood pressure erect and supine 120/80 $\mathrm{mm} \mathrm{Hg}$. Investigation showed anaemia (normochromic normocytic, haemoglobin $126 \mathrm{~g} / \mathrm{l}$ ) and hyponatraemia (plasma sodium of $116 \mathrm{mmol} / \mathrm{l}$, urea $4.7 \mathrm{mmol} /$, creatinine $60 \mu \mathrm{mol} / \mathrm{l})$. Plasma osmolality was $257 \mathrm{mmol} / \mathrm{kg}$ and urine osmolality $598 \mathrm{mmol} / \mathrm{kg}$, consistent with the syndrome of inappropriate secretion of antidiuretic hormone. A short tetracosactrin test, thyroid function tests, and chest radiography gave normal results. Radiography confirmed an osteoporotic fracture of L3. A screen for myeloma was negative. After fluid restriction and withdrawal of diclofenac nabumetone $1 \mathrm{~g}$ at night was substituted. The serum sodium and other biochemical values returned to normal (serum sodium $138 \mathrm{mmol} / \mathrm{l}$ ) within nine days.

The Committee on Safety of Medicines has received one report of fatal hyponatraemia in an 84 year old woman who took diclofenac $100 \mathrm{mg}$ daily (personal communication). Four similar cases have been attributed to piroxicam,' diclofenac, ${ }^{12}$ and ibuprofen. ${ }^{3}$ Ciba Geigy (UK) has received two further reports of hyponatraemia with diclofenac sodium (personal communication). Renal water reabsorption depends on the action of antidiuretic hormone, mediated by cyclic AMP (cAMP). Prostaglandins exert an inhibitory action by diminishing cAMP production, thus non-steroidal antiinflammatory drugs may cause water retention by potentiating the action of antidiuretic hormone. Our case suggests this effect may not be common to all classes of non-steroidal anti-inflammatory drugs.

Petersson I, Nilsson G, Hansson B, Hedner T Water intoxication associated with nonsteroidal anti-inflammatory drug therapy. Acta Med Scand 1987;221:221-3.

2 Dunn AM, Buckley BM. Non-steroidal antiinflammatory drugs and the kidney. $B M$ 1986;293:202-3.

3 Blum M, Aviram A. Ibuprofen induced hyponatraemia. Rheumatol Rehabil 1980;19: 258-9.

\section{Haemolytic uraemic syndrome during treatment with ketorolac trometamol}

Drs Maria luigia Randi, Tiziana Tison, Guido Luzzatto, and Antonio Girolami (Institute of Medical Semeiotics and 4th Chair of Medicine, Padua University School of Medicine, Padova, Italy) write: Renal injury is only rarely associated with the use of non-steroidal antiinflammatory drugs and then it is usually papillary necrosis and chronic interstitial nephritis following long term use of such drugs.' ${ }^{\prime}$ Nonsteroidal anti-inflammatory drugs, have in fact, little effect on renal function in normal people and may precipitate renal failure only in sodium deplete or hypovolaemic patients. ${ }^{2}$ Ketorolac trometamol, new non-steroidal anti-inflammatory drug, which seems to have more analgesic than anti-inflammatory and

antipyretic properties, ${ }^{3}$ has been associated with one case of acute renal failure, ${ }^{4}$ although its side effects are mainly gastrointestinal. We report a case of ketorolac induced microangiopathic haemolysis (haemolytic uraemic or Gasser's syndrome)

This 58 year old woman had an unremarkable history until 1991 , when she began complaining of arthralgias, occasionally treated with a pyrazolone derivative without any untoward effect. In March 1992 after three months without treatment, ketorolac trometamol $10 \mathrm{mg}$ twice a day was prescribed for recurrent arthralgia. Treatment was discontinued after a total dose of $30 \mathrm{mg}$ because of vomiting and bloody diarrhoea and she was admitted to our department the next day. On admission she had apparently already recovered, physical was negative, and routine laboratory values were all normal. She did well until the third day, when she again suffered nausea and vomiting. Oliguria, facial and peripheral oedema, and hypertension also appeared. Haemolytic anaemia (haemoglobin $90 \mathrm{~g} /$, packed cell volume $25 \%$, unconjugated bilirubin $56.4 \mu \mathrm{mol} / \mathrm{l})$, thrombocytopenia $\left(39 \times 10^{\circ} / 1\right)$, high levels of lactate dehydrogenase $(1 \cdot 188 \mathrm{U} / \mathrm{l})$ and D-dimer $(925 \mu \mathrm{g} / \mathrm{l})$ with decreased fibrinogen values $(2 \cdot 1 \mathrm{~g} / 1)$, and renal insufficiency (blood urea nitrogen $24 \mathrm{mmol} / \mathrm{l}$, creatinine $250 \mu \mathrm{mol} / \mathrm{l}$ ) with mild proteinuria $(2 \cdot 89 \mathrm{~g} / 24 \mathrm{~h})$ were detected. Coombs test was negative and no red cell enzyme deficiencies were detected. The laboratory and clinical picture of microangiopathic anaemia was confirmed by the presence of schistocytes on peripheral blood smears. Frusemide and non-specific supportive care were administered and the patient rapidly recovered. All laboratory values were back to normal in eight days. Neither malignancy nor infection could be recognised and no drug other than ketorolac had been given. Ketorolac was therefore probably responsible for the syndrome. To our knowledge only one case of drug induced haemolytic-uraemic syndrome has been reported among non-steroidal anti-inflammatory drugs, ${ }^{5}$ and this is the first one attributable to ketorolac. 